\title{
O ENSINO COMUNICATIVO DE LÍNGUAS ESTRANGEIRAS E A ABORDAGEM NATURAL
}

\author{
Cleci Irene TRENTIN
}

\begin{abstract}
Resumo: O movimento comunicativo tem suas origens a partir de teóricos funcionalistas. Em 1972, o lingüista britânico, David Wilkins, escreveu um documento preliminar que serviria de base para se desenvolver currículos comunicativos para o ensino de línguas. A rápida aceitação dessas idéias por especialistas britânicos e por autores de renome, deu proeminência nacional e internacional ao ensino comunicativo de línguas, o que acabou consolidando o que se chamou Abordagem Comunicativa (também chamada de abordagem nocional-funcional ou abordagem funcional). Vários autores têm desenvolvido teorias compatíveis com os princípios da Abordagem Comunicativa os quais, se discordam em alguns pontos, concordam que o principal objetivo do ensino de línguas estrangeiras é o uso da linguagem para a comunicação. Entre esses autores destaca-se Stephen Krashen e as suas cinco (5) hipóteses apresentadas no The Natural Approach.
\end{abstract}

\section{As Origens}

O movimento comunicativo tem suas origens a partir de teóricos funcionalistas da Escola de Praga e da Tradição Britânica.

A Escola de Praga dedicou-se ao estudo da morfologia e da fonologia e, através de Mathesius (In Berns, 1990), também fez estudos no nível da sentença, destacando a função de cada parte da sentença sobre a forma. Conforme Berns (1990), este autor identifica as necessidades comunicativas e expressivas do discurso como ponto inicial para uma análise lingüística.

A tradição britânica, especialmente através dos trabalhos de John Firth (1930, 1937), se fundamenta na mútua dependência entre língua, cultura e sociedade. A língua deve ser vista como parte do processo social, pois a sua função é a de ser o meio pelo qual as pessoas funcionam, fazem coisas na sociedade. Firth $(1930,1937)$ também enfatiza a importância do significado e do contexto. O significado é a função que a língua desempenha no contex to e está relacionado ao uso de determinadas formas e elementos lingüísticos em contextos específicos. Quanto ao contexto, Firth "o vê mais do que o ambiente de uma situação, constituindo-se na relação entre língua e todos os vários aspectos da situação em que ela é usada, ao que o autor chama de contexto de situação". (Berns, 1990, p. 56).

Influenciado pelas correntes funcionalistas acima, M. A. K. Halliday $(1970,1975)$ desenvolveu a sua gramática sistêmico-funcional. Esta gramática busca estabelecer relações entre todas as escolhas semanticamente relevantes feitas na língua como um todo, assim, chegaríamos à resposta do porquê determinado falante escolhe determinados itens dentre tantos disponíveis naquela língua para fazer o seu enunciado. A partir das funções comunicativas da linguagem, que já haviam sido estudadas por Firth, Halliday (1975), que em 1970 havia proposto um sistema descritivo para a linguagem do adulto, afirma que a linguagem da criança pode ser descrita em termos de 
seis categorias funcionais: as funções instrumental, regulatória, interacional, pessoal, eurística e imaginativa.

A teoria chomskyana, com seus pressupostos, especialmente do inatismo e da competência lingüística, foi outro aspecto que influenciou a mudança no ensino de línguas estrangeiras e direcionou para uma nova abordagem. O inatismo, segundo Noam Chomsky (1965), seria a capacidade inata que o indivíduo tem para adquirir a linguagem através do LAD (Language Acquisition Device), órgão que, juntamente com outros, propiciaria a aquisição da língua materna; e a competência lingüística seria a capacidade que todo falante nativo tem de adquirir a gramática implícita de sua língua materna pela exposição natural a ela. Este pressuposto considera a existência de uma gramática universal, comum a todos os falantes. O enfoque da teoria lingüística de Chomsky (1965) se concentrava nas habilidades abstratas que os falantes possuem capacitando-os a produzir sentenças gramaticalmente corretas em uma língua.

Nenhum método foi desenvolvido para o ensino de línguas estrangeiras a partir da teoria de Chomsky (1965), entretanto, a visão de que a competência lingüística não estava relacionada à formação de hábito, mas a sistemas de aquisição internos do indivíduo, provoca uma mudança na maneira de se encarar o ensino de línguas estrangeiras.

Assim, a contribuição de Firth $(1930,1937)$ para a Abordagem Comunicativa está na visão da língua como interação; Halliday $(1970,1975)$ colabora com a noção de função e Chomsky (1965) com a crítica à teoria behaviorista para o ensino de línguas estrangeiras.. Além da contribuição dessas teorias, dos trabalhos americanos de sociolingüística como de Dell Hymes (1972), John Gumperz (1972) e William Labov (1970), estudiosos como Chistopher Candlin (1976) e Henry Widdowson (1978), que defendiam o enfoque do ensino de línguas na proficiência comunicativa, mais do que no domínio de estruturas, contaram também com os trabalhos de filosofia de John Austin (1962) e John Searle (1969).

Em 1972, o lingüista britânico David Wilkins escreveu um documento preliminar que serviria de base para se desenvolver currículos comunicativos para o ensino de línguas.

A contribuição de Wilkins

foi uma análise dos significados comunicativos que um aprendiz de línguas precisa entender e expressar. Mais do que descrever a essência da língua através de conceitos tradicionais de gramática e vocabulário, Wilkins tentou demonstrar os sistemas de significado que estavam por trás do uso comunicativo da língua. (Richards \& Rodgers, 1994, p.65) 
Nesse documento, Wilkins descreveu dois tipos de significados: as categorias nocionais como tempo, seqüência, quantidade, localização e freqüência e categorias de funções comunicativas como pedidos, negações, oferecimentos, etc. Mais tarde, depois de revisado e ampliado, o documento de Wilkins toma a forma de livro e é publicado em 1976, com o título de Notional Syllabuses dando origem ao método Nocional/funcional, onde juntaram-se às funções (coisas que se pode fazer com a língua), as noções (idéias expressas por nós).

A rápida aceitação dessas idéias por especialistas britânicos e por autores de renome, deu proeminência nacional e internacional ao ensino comunicativo de línguas, o que acabou consolidando o que se chamou Abordagem Comunicativa (também chamada de abordagem nocional-funcional ou abordagem funcional).

Conforme Richards \& Rodgers (1994), como teoria de linguagem a Abordagem Comunicativa tem uma rica e um tanto eclética base teórica. Algumas das características são as seguintes: a língua é um sistema para expressão do significado; a principal função da linguagem é interação e comunicação; a estrutura da língua reflete seu uso funcional e comunicativo; as principais unidades de linguagem não são meramente suas características gramatical e estrutural, mas categorias de significado funcional e comunicativo.

Em relação à teoria da aprendizagem podem ser relacionados os seguintes princípios comunicativos:

\author{
Atividades que envolvem \\ real comunicação \\ promovem \\ aprendizagem.(...) Princípio \\ de tarefas: atividades nas \\ quais a língua é usada para \\ realizar tarefas \\ significativas promovem \\ aprendizagem. (...) princípio \\ do significado: a linguagem \\ que é significativa para o \\ aprendiz auxilia no processo \\ de aprendizagem. (Richards \\ \& Rodgers, 1994, p.72)
}

Vários autores têm desenvolvido teorias compatíveis com os princípios da Abordagem Comunicativa como Savignon (1983), Johnson \& Littlewood (1984), Widdowson (1979), Almeida Filho (1993, 1997), Krashen (1981, 1982, 1983), entre outros que, se discordam em alguns pontos, concordam que o principal objetivo do ensino de línguas estrangeiras é o uso da linguagem para a comunicação.

Considerando-se que os professores envolvidos nesta pesquisa não só estudaram e analisaram, mas tentam aplicar a teoria de aquisição de segunda língua proposta por KRASHEN \& TERREL e que as categorias levantadas para a análise dos dados desta pesquisa estão diretamente relacionadas a essa teoria, passaremos a expor as idéias de Krashen relativas ao ensino/ aprendizagem de língua estrangeira. 


\section{A Teoria de Krashen}

Stephen KRASHEN (1981, 1982, 1985, 1987) (da University of Southern California) é um dos pioneiros do movimento comunicativo e formulou uma teoria de aquisição de segunda língua ou língua estrangeira, a qual é composta de cinco (5) hipóteses: a distinção entre aquisição e aprendizagem de uma língua; a ordem natural; o monitor; o insumo e o filtro afetivo.

\section{Hipótese de Aquisição e Aprendizagem de uma Língua}

Segundo Krashen uma pessoa pode desenvolver a competência

em uma segunda língua de duas maneiras: através da aquisição (acquisition) ou através da aprendizagem (learning).

A aquisição de uma língua se dá através de um processo subconsciente, similar, se não idêntico, à forma como as crianças desenvolvem a habilidade na primeira língua. Normalmente, as pessoas não estão conscientes do fato de que estão adquirindo a linguagem, mas estão conscientes de que elas a estão usando para a comunicação. Não há preocupação com as regras e as sentenças gramaticais "soam" ou "sente-se" que elas estão certas ou erradas, mas não se sabe que regra foi violada.

A aprendizagem (learning) refere-se ao conhecimento consciente de uma segunda língua, o conhecimento das regras, estar consciente delas e ser capaz de falar sobre elas. É o conhecimento formal da língua. "Learning" é aprender sobre a língua.

\section{Hipótese da Ordem Natural}

Krashen, Dualey \& Burt (1974, 1975) e Brown (1973) afirmam existir uma ordem natural para a aquisição de alguns morfemas gramaticais. Isto quer dizer que alguns morfemas seriam adquiridos antes e outros mais tarde.

Brown (1973), por exemplo, nos afirma que a criança que está aprendendo Inglês como primeira língua aprenderia primeiro os morfemas "ing" (que marca o tempo progressivo) e o "s" que marca o plural; mais tarde ela iria adquirir o "s" que marca a $3^{\text {a }}$ pessoa do singular e o caso genitivo.

Krashen afirma que a ordem de aquisição para uma segunda língua não é a mesma que a ordem de aquisição para a primeira língua, entretanto, existem similaridades e, embora a língua inglesa seja a mais estudada neste sentido, estudos com outras línguas também demonstram que existe uma ordem natural para a aquisição de uma língua, seja ela, língua materna, língua estrangeira ou segunda língua.

Outro ponto a ser abordado sobre a Hipótese da Ordem Natural é que ela se aplica somente no caso de aquisição da língua, pois a aprendizagem causa uma ordem não natural e conseqüentemente a monitoração da produção.

\section{Hipótese do Monitor}


A Hipótese do Monitor diz respeito ao uso de regras formais na realização de uma segunda língua. Para que um falante possa usar as regras conscientemente, são necessárias três condições:

1. Tempo-para que um falante possa pensar o que vai falar e usar efetivamente as regras, ele precisa dispor do tempo necessário para isso, entretanto, o excesso de uso de regras na conversação pode levar à confusão, a um estilo hesitante de falar e à desatenção em relação àquilo que o seu interlocutor está falando, por isso esta hipótese está mais ligada à aprendizagem da língua e não à aquisição.

2. Enfoque na forma - Não apenas o tempo é necessário para o falante usar o Monitor; é também necessário o enfoque na forma, ou pensar sobre a correção. $\mathrm{O}$ falante preocupase mais com a forma como vai transmitir a mensagem do que com a própria mensagem.

3. Saber as regras - para que o falante possa usar o Monitor é necessário que ele conheça as regras gramaticais, pois a correção só poderá se efetuar se o falante puder distinguir a forma correta da não correta.

Krashen nos diz que existem três tipos básicos de usuários do monitor aos quais ele denomina de : a) Monitor Over-user; b) Monitor Under-user e c) Optimal Monitor user.

O primeiro tipo (Monitor over-user) refere-se às pessoas que usam o monitor o tempo todo e constantemente examinam a sua produção com seu conhecimento consciente da segunda língua. Este usuário, normalmente, possui fala hesitante e preocupa-se demais em corrigir-se, assim, ele não consegue falar fluentemente.

O segundo tipo (Monitor under-user) refere-se às pessoas que não aprenderam sobre a língua ou, se aprenderam, preferem não usar o seu conhecimento consciente sobre ela. Estas pessoas, normalmente, "sentem" se a sua produção está ou não correta, possuem fluência, pois adquiriram a segunda língua e não estão preocupadas se a sua produção está formalmente correta.

O terceiro tipo (Optimal Monitor user) refere-se às pessoas que usam o Monitor de forma apropriada e quando não interfere na comunicação. Optimal users não usam o Monitor quando este irá interferir na sua produção. Krashen nos diz que Optimal users usam a competência aprendida como um complemento à competência adquirida.

\section{Hipótese do Input}

A Hipótese do Input se relaciona à aquisição e não à aprendizagem e tenta explicar como acontece a aquisição da língua à qual o aprendiz está exposto. "Quando a aquisição (...) está acontecendo existem estágios nos quais o aluno está recebendo linguagem - linguagem que de alguma maneira está sendo posta dentro do aluno (embora eles decidam se querem ou não recebê-la)." (Harmer, 1994, p. 40)

A essa linguagem nova é que Krashen denomina de Input. Segundo Krashen, $o$ input pode advir dos materiais, do professor e dos próprios alunos. Este input deve ser compreensível aos alunos, portanto deve estar um pouco acima do seu nível de competência para que ocorra a aquisição da língua e o aluno possa mudar do estágio $i$ 
(onde $i$ significa o nível atual de competência do aluno) para o estágio $i+1$ (onde $i+1$ significa o estágio imediatamente superior a $i$ ).

O input fornecido se torna compreensível através da situação e contexto em que é apresentado, informação extralingüística e conhecimento de mundo que o aprendiz possui. Entretanto, o input não precisa estar estritamente ligado ao atual nível de competência dos aprendizes (mesmo porque isto não é possível, pois em uma sala de aula de línguas haverá vários diferentes níveis de competência lingüística) pois, conforme Krashen, quando o falante usa uma linguagem através da qual o adquirente entende a mensagem, o falante projeta uma rede envolvendo o atual nível de competência do receptor.

Para o fornecimento de input, também pode ser usado o foreigner talk (conversa de estrangeiro), que se refere ao discurso que os falantes usam para simplificar a conversação e se caracteriza por uma velocidade mais lenta, repetição, exposição de outra forma e o uso de questões com respostas de sim/não, para que possa ocorrer comunicação entre participantes. Assim, conforme a teoria de Krashen, as aulas devem ser na língua alvo, sem o uso da língua materna.

De acordo com essa hipótese, o aprendiz progride de forma natural quando ele recebe o input de segunda língua.

\section{Hipótese do Filtro Afetivo}

De acordo com Krashen, os fatores afetivos influenciam na aquisição de uma segunda língua porque os aprendizes variam de acordo com a força ou nível do filtro afetivo. Os aprendizes cujas atitudes afetivas não são favoráveis à aquisição de uma língua estrangeira têm um filtro afetivo alto. Aqueles que estão mais predispostos a adquirir a língua estrangeira têm um filtro afetivo mais baixo. Assim, o filtro afetivo age no sentido de facilitar ou evitar a aquisição da língua alvo. Baseado em uma pesquisa sobre aquisição de segunda língua que identificou três tipos de variáveis afetivas, Krashen construiu a sua hipótese do filtro afetivo. As três variáveis são motivação, autoconfiança e ansiedade.

Baixa motivação, falta de autoconfiança e autoestima e ansiedade (tanto individual, como do grupo) combinam-se para aumentar o filtro afetivo e formam uma espécie de bloqueio mental que não permite que o input compreensível seja usado na aquisição da LE. Por outro lado, um ambiente de sala de aula com baixa tensão, onde os alunos se sentem estimulados, favorece a aquisição da língua alvo.

Conforme Richards \& Rodgers (1994, p.133) estas cinco hipóteses têm implicações óbvias no ensino de línguas, que, em resumo são:

Quanto mais compreensível o input, maior é a possibilidade de ser apresentado.

O que quer que seja que ajude a compreensão é importante. Recursos visuais são úteis, pois é exposição a uma ampla variedade de vocabulário, mais do que o estudo de estrutura sintática.

$\mathrm{O}$ enfoque na sala de aula deve ser no listening e reading: o speaking deve emergir. 
A fim de abaixar o filtro afetivo, o trabalho do aluno deve estar centrado na comunicação significativa, mais do que na forma; o input deve ser interessante e assim contribuir para uma atmosfera relaxada de sala de aula.

Além dessas hipóteses, Krashen (1987) estabelece quatro princípios para o ensino/aprendizagem de línguas estrangeiras, conforme o Natural Approach.

O primeiro princípio diz respeito à compreensão. Segundo Krashen, a compreensão precede a produção, isto é, a compreensão de listening (ou reading) precede as habilidades de speaking (ou writing). Isto decorre das hipóteses apresentadas anteriormente, tendo em vista que a aquisição é a base para a habilidade de produção e, a fim de que ocorra aquisição, o aluno deve entender as mensagens. Assim, o ponto inicial na instrução de língua é ajudar os alunos a entenderem o que está sendo dito para eles. Deste princípio decorrem algumas implicações. Primeiro, em sala de aula, o professor sempre deve usar a língua alvo, neste caso o Inglês. Segundo, o enfoque da comunicação será sobre um tópico de interesse do aluno e, terceiro, o professor deve ajudar o aluno a entender aquilo que está em estudo.

O segundo princípio geral do Natural Approach é que se permite que a produção aconteça em estágios. Estes estágios tipicamente consistem de: (1) resposta por comunicação não verbal, (2) resposta com uma única palavra, (3) combinações de duas ou três palavras, (4) frases, (5) sentenças e, finalmente, (6) discurso mais complexo. A precisão gramatical é muito baixa nos estágios iniciais e aumenta lentamente com o aumento das oportunidades de interação comunicativa e aquisição. Por esta razão, no Natural Approach, os alunos não são forçados a falar antes que eles estejam prontos. Ainda, erros de discurso que não interferem na comunicação não são corrigidos; enquanto a correção de erros pode ajudar na aprendizagem, a competência adquirida origina-se do input compreensível.

O terceiro princípio geral do Natural Approach é que o currículo do curso é organizado por tópico, não por estrutura gramatical. Assim, um possível objetivo pode ser aprender a comunicar sobre viagens que os alunos fizeram ou ser capaz de pedir um menu em um restaurante. A prática específica de estruturas gramaticais não é enfocada nestas atividades. Krashen afirma que a gramática será efetivamente adquirida se os objetivos são comunicativos. Se os objetivos são gramaticais, o aluno poderá aprender um pouco de gramática, mas muito pouco será adquirida. Assim, mesmo que nós estejamos interessados em produzir estudantes que possam falar com correção gramatical, a habilidade comunicativa é enfatizada e não a precisão gramatical, na compreensão inicial e nos estágios de produção.

O último princípio proposto por Krashen (1987), é que as atividades feitas em sala de aula que objetivam aquisição, inicialmente, devem abaixar o filtro afetivo dos alunos. As atividades de sala de aula sempre devem enfocar tópicos que são interessantes e relevantes para os alunos e os encorajar a expressarem suas idéias, opiniões, desejos, emoções e sentimentos. Um ambiente que conduz à aquisição deve ser criado pelo professor - baixo nível de ansiedade, boa harmonia com o professor, relacionamento amigável com outros alunos; de outra maneira a aquisição será impossível. Tal atmosfera não é um luxo, mas uma necessidade. 


\section{O papel do professor e aluno no processo de ensino/aprendizagem de LE, segundo a teoria de Krashen}

Segundo essa teoria, o professor possui três papéis centrais. Primeiro, o professor é a principal fonte de input da língua alvo, assim ele deve produzir um fluxo constante de linguagem e ao mesmo tempo fornecer pistas para auxiliar os alunos na interpretação do input. Segundo, o professor deve criar uma atmosfera favorável, que seja interessante e amigável para que se obtenha um baixo filtro afetivo. $\mathrm{O}$ assunto da aula deve ser de interesse dos alunos e não se deve corrigir os seus erros. Finalmente, o professor deve escolher e dirigir uma grande variedade de atividades de sala de aula, envolvendo variados grupos, conteúdo e contextos. Os materiais devem estar baseados não apenas na percepção do professor, mas também nos interesses e necessidades dos alunos.

O papel do aluno muda de acordo com o estágio de desenvolvimento lingüístico. É ele quem decide quando falar, o que falar e que expressões usar. $\mathrm{O}$ aluno é desafiado pelo input que está ligeiramente além de seu nível de competência lingüística a desvendar o significado desse input, através do contexto e conhecimento extralingüístico.

Inicialmente, eles não precisam responder na língua alvo. Eles podem participar usando comandos através de gestos, identificar colegas através da descrição do professor, apontar para figuras, etc. Em seguida, eles podem usar palavras simples, fazer e responder a questões simples, como what's your name?, etc. e usar modelos de conversação. Finalmente, eles participam de role-plays, jogos, dão opiniões e informações pessoais e resolvem problemas em grupo.

\section{Considerações finais}

Pelo exposto, a Abordagem Natural está estritamente ligada ao Ensino de Línguas Comunicativo, especialmente porque:

a. os tópicos estudados devem ser relevantes, significativos para o aluno e, portanto, devem estar relacionados a sua vida diária;

b. o ensino de línguas estrangeiras está baseado em funções comunicativas, priorizando a comunicação interativa entre os sujeitos de sala de aula.

Finalmente, a Abordagem Comunicativa e a Abordagem Natural respeitam a evolução natural e individual do aprendizado da língua estrangeira pelo aluno.

\section{REFERÊNCIAS BIBLIOGRÁFICAS}

AUSTIN, J. L. How to do things with words. Oxford, Carendon Press. 1962. 
BERNS, M. Contexts of competence. New York, Plenum Press, 1990. Resenhado por BASSO, E. Universidade Estadual de Campinas.

BREEN, P. M. \& CANDLIN, C. N. The essentials of a communicative curriculum in language teaching. Applied Linguistics. London, Oxford University Press, v.4, n.2., 1981.

BROWN, H. D. Teaching by principles - An interactive approach to language pedagogy. Upper Saddle River, Prentice Hall Regents, 1994.

CHOMSKY, N. Knowledge of language; its nature, origin and use. New York, Praeger, Série Convergence, 1986.

FIRTH, J.R. Papers in linguistics. London, Oxford University Press. 1957.

GUMPERZ, J.J. \& HYMES, D. The ethnography of communication. New York, Holt, 1972.

HALLIDAY, M. A. K. Language structure and language function. In J. Lyons, New Horizons in Linguistics. Harmondsworth, Penguin, 1970.

Edward Arnold, 1973.

Explorations in the functions of language. London,

. Learning how to mean: explorations in the development of language. London, Edward Arnold, 1975.

HARMER, J. The practice of English language teaching. London, Longman, 1994.

HYMES, D. On communicative competence. Sociolinguistics. Harmondsworth, Penguin, 1972.

JOHNSON, J. Communicative syllabus design and methodology. Oxford, Pergamon. 1982.

KRASHEN S. D. Second language acquisition and second language learning. Oxford, Pergamon, 1981.

Principles and practices in second language acquisition.

New York, Pergamon Press, 1982.

The input hypothesis: issues and implications. London,

Longman, 1985

KRASHEN, S. D. \& TERREL, T. The natural approach. Language acquisition in the classroom. San Francisco, Alemany Press, 1987.

LITTLEWOOD, W. Communicative language teaching. Cambridge, Cambridge. 1981. 
RICHARDS, J. \& RODGERS, T. Approaches and methods in language teaching. Cambridge, Cambridge University Press. 1994.

SAVIGNON, S. J. Communicative competence: theory and classroom practice. Massachussets, Addison-Wesley, 1983.

SAVIGNON, S. J. \& BERNS, M. S. Initiatives in communicative language teaching II. A book of readings. New York, Addison-Wesley, 1987.

SEARLE, J. R. Speech acts: an essay in the philosophy of language. Cambridge, Cambridge. 1969.

WIDDOWSON, H. G. Teaching language as communication. Oxford, Oxford University Press, 1978.

WILKINS, D. A. Notional syllabuses. Oxford, Oxford University Press, 1976. 